\title{
Evaluación del contenido de metabolitos secundarios en dos especies de plantas forrajeras encontradas en dos pisos térmicos de Colombia
}

\author{
Luz Elena Santacoloma-Varón ${ }^{1}$ \& Jairo Enrique Granados ${ }^{2}$ \\ ${ }^{1}$ mluz.santacoloma@unad.edu.co, ${ }^{2}$ jairo.granados@unad.edu.co \\ CEAD José Celestino Mutis \\ Universidad Nacional Abierta y a Distancia
}

\begin{abstract}
Resumen.- Recolectamos muestras de dos especies forrajeras: Gliricidia sepium, y Tithonia diversifolia en dos localidades en diferentes pisos térmicos (Tuluá $960 \mathrm{msnm}$ y Codazzi $131 \mathrm{msnm}$ ) y evaluamos el contenido de los taninos condensados y polifenoles totales, tomando muestras de hojas de tres zonas fotosintéticas de la planta. Aplicamos técnicas analíticas e instrumentales de la AOAC internacional para determinar la presencia de fitometabolitos secundarios. Encontramos que en $T$. diversifolia y en G. sepium no existen diferencias significativas en el contenido de polifenoles totales (PFT) y taninos condensados (TC) entre las dos zonas de la plantas, pero sí existe diferencia significativa entre las muestras provenientes de diferentes pisos térmicos.
\end{abstract}

Palabras clave: fitobiomoléculas leguminosa, metabolito, saponinas, taninos.

Abstract.- We evaluated Gliricidia sepium and Tithonia diversifolia from two different altitudes (Tuluá 960 masl and Codazzi 131 masl). We assess the content of hydrolyzable tannins and total polyphenols in three different parts of the plant, in order to identify the potential effect of altitude over secondary biomolecules concentration. We applied analytical and instrumental protocols of AOAC international to determine the presence of secondary metabolites. Two way ANOVA shows no-significant differences in the content of total polyphenols and condensed tannins in the different parts of the plant in neither T. diversifolia or G. sepium. We found significant differences in the content of total polyphenols within the altitude, but not for the part of the plant in which the sample was collected.

Key words: Metabolites, Phyto-biomolecules, Sponins, Tannins.

\section{Introducción}

Un gran número de árboles tropicales son forrajeros y ramoneables, por lo que constituyen un recurso alimenticio importante para los rumiantes debido a su alto contenido de proteína cruda y minerales. Sin embargo, muchas especies vegetales presentan metabolitos secundarios, como taninos, saponinas, compuestos fenólicos y alcaloides, que pueden tener un efecto negativo sobre el valor nutricional de estos forrajes. Estas sustancias son elaboradas por la planta y cumplen funciones como la defensa contra hongos, bacterias y virus, la protección contra la radiación ultravioleta y sirven además como mecanismo para evitar la deshidratación de sus tejidos. La presencia de estos componentes confiere a las plantas un sabor desagradable, que en muchos casos genera baja aceptabilidad para su consumo por parte de los animales herbívoros y hace que se disminuya la presión de pastoreo.

Existe una gran variación cualitativa y cuantitativa en el contenido de metabolitos secundarios entre diferentes especies vegetales. El contenido de estas sustancias puede alcanzar hasta un $40 \%$ de la materia seca dependiendo de factores climáticos, edafológicos y de la parte de la planta en que se encuentren. $\mathrm{Ku}$ mar (1992) encontró que los distintos compuestos que puede producir una especie presentan una determinada distribución dentro de los órganos, tejidos y células de una planta, $y$ ello responde frecuentemente a las influen- 
cias ambientales.

Siguiendo un criterio biosintético, los productos naturales secundarios podrían dividirse en tres grandes grupos de compuestos: nitrogenados, terpénicos y fenólicos. Los primeros, entre los que se encuentran los alcaloides, se derivan principalmente de los aminoácidos. Los terpenos por su parte, se obtienen a través de la ruta del mevalonato mientras que los fenóles se derivan a partir de la ruta del ácido shikímico o de la ruta del malonato (De Troiani 2005).

Las saponinas son biomoléculas que, en forma glucosídica, actúan como esteroides reguladores del crecimiento y pueden generar en las plantas un aumento en el crecimiento y desarrollo de la planta, además de una rápida recuperación luego de la poda, mediante la presencia de brotes abundantes (Ashok et al. 2000). Adicionalmente, teniendo en cuenta las concentraciones y las estructuras químicas específicas, los compuestos saponínicos pueden constituir factores anti-nutricionales en rumiantes y monogástricos, ya que confieren a los forrajes un sabor amargo, producen espumas consistentes, e interfieren en la absorción de los nutrientes (Kumar 1992). No obstante, también pueden tener un efecto positivo en el metabolismo digestivo, al formar complejos con otros metabolitos secundarios con características tóxicas, recudiendo su efecto nocivo (Makkar et al. 1995).

Otro grupo de metabolitos secundarios de singular importancia es el de los taninos. Estos polifenoles solubles en agua, están presentes en casi todas las plantas y particularmente en las dicotiledóneas, de las cuales hacen parte las leguminosas (Posada \& Montoya 2005). Los factores que afectan el contenido de taninos en los árboles son: genética de la planta, especie, grado de madurez, estación climática, humedad, estado de crecimiento, luminosidad, corte y defoliación por herbívoros (Norton \& Ahn 1997). También se ha encontrado que la planta produce y acumula diferentes cantidades de metabolitos en cada una de sus partes (Fedoreyev et al. 2000, Oncina et al. 2000y que la temperatura también afecta la producción de metabolitos secundarios, aunque no se conocen con claridad los mecanismos bioquímicos por los que esto ocurre. Se ha propuesto también que el estrés térmico estimula la producción (Georgiev et al. 2004), generan- do cambios en los procesos de transducción de señales al interior de la célula que activan tanto la transcripción de genes, como enzimas específicas involucradas en la síntesis de estos metabolitos. Además, el fotoperiodo, la relación luz/oscuridad y la duración del periodo, pueden afectar el crecimiento, producción y acumulación interna de metabolitos secundarios como se ha encontrado en cultivos de C. arabica (Zhang et al. 2002) y Podophyllum hexandrum (Chattopadhyay et al. 2002). Otro factor ambiental de alta incidencia en la concentración de taninos es la fertilidad del suelo. Barry y Forss (1983) encontraron una concentración de taninos condensados (TC) de 8 al $11 \%$ en Lotus pedunculatus creciendo en suelos ácidos sin aplicación de fertilizantes, mientras que los valores eran tan solo de 2 al 3\% en suelos fertilizados. La baja disponibilidad de agua también contribuye a la producción de TC, debido a que, en tales circunstancias las plantas cierran sus estomas y restringen el proceso de fotosíntesis.

La concentración de metabolitos secundarios afecta la digestión en rumiantes, ocasionando un descenso en la digestibilidad de la materia orgánica en el rumen cuando consumen forrajes con altos contenidos de metabolitos secundarios, particularmente de taninos, debido a que algunos de éstos tienen un efecto inhibidor sobre la actividad de las enzimas digestivas (Leinmúller et al. 1991). Los taninos también inhiben la degradación de la proteína en el rumen disminuyendo las concentraciones de amonio, lo que sugiere una inhibición de las enzimas proteolíticas a este nivel (Norton \& Ahn 1997).

En el presente trabajo buscamos evaluar el contenido de metabolitos secundarios en tres zonas fotosintéticas en árboles de Gliricidia sepium y Tithonia diversifolia procedentes de dos pisos térmicos de Colombia, en busca de diferencias en la concentración de polifenoes totales (PFT) y taninos concentrados (TC) en dos zonas fotosintéticas de los árboles, además de las variaciones relacionadas con el piso térmico en que se encuentran.

\section{Materiales y métodos}

Seleccionamos dos localidades ubicadas diferentes pisos térmicos. La primera en el departamento de Cesar, en el municipio de Codazzi, a $131 \mathrm{msnm}$ y la segunda se encuentra en el 
Valle del Cauca, en el municipio de Tuluá, a 960 m de altitud. En cada uno de estos sitios elegimos un árbol de G. sepium y otro de T. diversifolia por ser especies forrajeras y ramoneables. Recogimos seis hojas de cada árbol, tomadas de la zona alta o fototrópica (ZA), de la zona media (ZM) y de la zona baja o geotrópica (ZB). Este material fue empacado en bolsas negras rotuladas adecuadamente y llevadas hasta el laboratorio de nutrición de la sede nacional José Celestino Mutis de la Universidad Nacional Abierta y a Distancia, en la ciudad de Bogotá D.C., donde se realizaron los respectivos análisis químicos. Dichos análisis tuvieron en cuenta la composición química proximal, con el fin de conocer el estado nutricional de los forrajes y luego se aplicaron las técnicas analíticas e instrumentales de la AOAC (2005) para determinar la presencia de dos tipos de metabolitos secundarios: polifenoles totales (PFT) y taninos condensados (TC).

Para el análisis de datos utilizamos un muestreo bifactorial al azar, con dos variables: la altitud a la que se tomaron las muestras (localidad) y las zonas de muestreo en el árbol y aplicando un modelo lineal aditivo (GLM), análisis de varianza (ANAVA) en doble vía y un test de comparación múltiple, para lo cual utilizamos los paquetes estadísticos STATGRAPHICS y S.A.S( versión para Windows.,2004)

\section{Resultados}

La muestra de T. diversifolia tomada a $960 \mathrm{~m}$ de altitud (Tuluá) presentó mayor contenido de PFT y TC que la tomada a $131 \mathrm{~m}$ (Codazzi) (Tabla 1). En los dos casos hubo diferencias significativas en los contenidos de metabolitos secundarios, cuya concentración fue mayor en

Tabla 1. Valores porcentuales promedio de PFT y TC en Thitonia diversifolia a nivel de las regiones evaluadas

\begin{tabular}{cccc}
\hline Indicador & \multicolumn{2}{c}{ Regiones } & Significancia \\
\hline & Codazzi & Tuluá & \\
PFT (\%) & 0.043 & 0.262 & $* *$ \\
TC (\%) & 0.310 & 0.491 & $*$ \\
\hline & & PFT: Polifenoles totales \\
& & TC: Taninos condensados \\
& & \\
& & & $P<0.01,{ }^{*} \mathrm{P}<0.05$
\end{tabular}

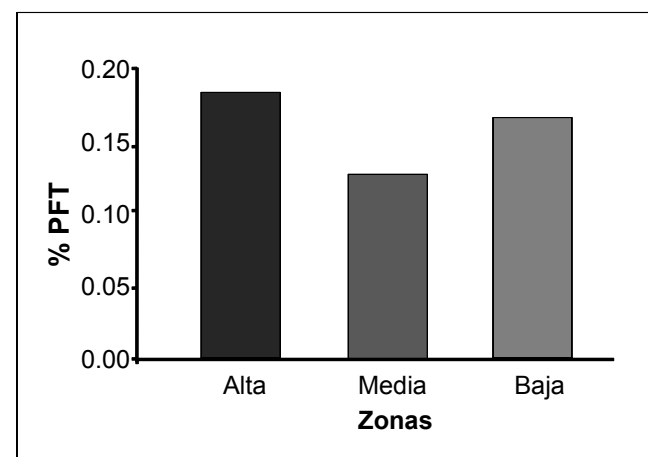

Figura 1. Análisis comparativo de la concentración de polifenoles totales en $T$. diversifolia en las diferentes zonas de la planta

las muestras tomadas a mayor altitud.

Un comportamiento similar fue encontrado en G. sepium (Tabla 2). El promedio de PFT y TC contenido en las hojas fue significativamente mayor en las muestras tomadas en Tuluá con respecto a las de la región de Codazzi. La muestra de Tuluá superó en $2.51 \%$ en el contenido de PFTa la obtenido en Codazzi y a en cuanto a TC, esta última obtuvo $0.18 \%$ menos que la tomada a mayor altitud.

El tcontenido de metabolitos secundarios (PFT y TC) presentaron diferencias significativas entre las muestras tomadas en las dos localidades (Tabla 1 y2), sugiriendo que la altitud constituye un factor determinante de la cantidad de PFT y TC en estas especies de árboles ( $T$. diversifolia y G. sepium). El contenido de metabolitos secundarios fue superior en las muestras tomaras en Tuluá, a mayor altitud.

Tabla 2. Valores porcentuales promedio de PFT y TC en Gliricida sepium a nivel de las regiones evaluadas

\begin{tabular}{cccc}
\hline Indicador & \multicolumn{2}{c}{ Regiones } & Significancia \\
\hline & Codazzi & Tuluá & \\
PFT (\%) & 0.050 & 3.01 & $* *$ \\
TC (\%) & 0.31 & 0.49 & $*$ \\
\hline & & PFT: Polifenoles totales \\
& & TC: Taninos condensados \\
& & \\
& & $P$ & $\mathrm{P}<0.01,{ }^{*} \mathrm{P}<0.05$
\end{tabular}




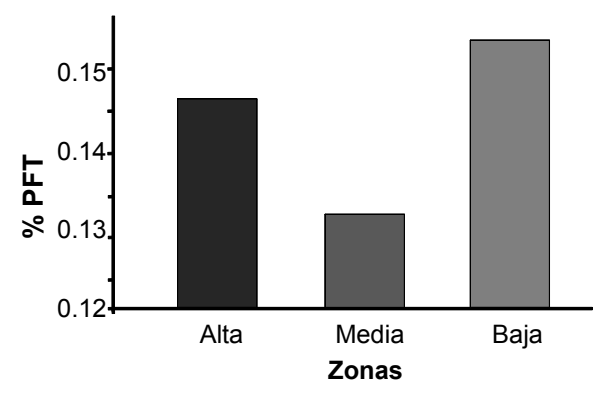

Figura 2. Análisis comparativo de la concentración de polifenoles totales en $G$. sepium en las diferentes zonas de la planta

Por otro lado, el contenido de PFT en las hojas de $T$. diversifolia (Fig. 1) fue menor al $0.20 \%$ en las tres zonas fotosintéticas del árbol, sin presentar diferencias estadísticamente significativas; de forma similar en la muestra de $G$. sepium, el contenido foliar de PFT fue siempre inferior al $0.15 \%$ (Fig. 2).

\section{Discusión y Conclusiones}

La ausencia de una diferencia significativa en el contenido de PFT y TC entre las diferentes zonas del árbol de $T$. diversifolia contrasta con lo esperado. De acuerdo con Georgiev y colaboradores (2004)., en las zonas más cálidas el contenido de PFT debería ser mayor, debido a que las hojas interceptan una mayor proporción de la luz incidente, que le proporciona a la planta un crecimiento más rápido y en consecuencia una mayor producción de metabolitos primarios y secundarios (Además, encontramos que sí existe una diferencia significativa entre el contenido de PFT y TC en los árboles provenientes de los diferentes pisos térmicos, lo cual contrasta con lo encontrado por Sierra (2006), quien planteó que a mayor temperatura ambiental, se presenta una mayor velocidad de las reacciones bioquímicas del organismo.

En G. sepium no se presentó diferencia significativa en el contenido de polifenoles totales ni de taninos hidrolizables por efecto de la zona de la planta, demostrándose que la concentración de estos metabolitos es igual tanto en la parte alta, media o baja de la planta. Es decir, que en esta especie el efecto del autosombreamiento no incide en la producción de metabolitos secundarios hubo una diferencia significativa en PFT y TC causada por la diferencia en altitud. La mayor concentración de PFT se obtuvo en la muestra tomada en Tuluá con temperaturas que oscilan entre 26 y $28^{\circ} \mathrm{C}$. En Codazzi, aunque la temperatura promedio es mayor, obtuvimos una menor concentración de PFT, probablemente, porque la muestra fue tomada en época seca y esto puede afectar las tasas fotosintéticas y en consecuencia la síntesis de metabolitos secundarios. Es necesario tener en cuenta que, aunque el volumen y velocidad de las reacciones bioquímicas puede aumentar con la temperatura, la mayoría de reacciones químicas en las plantas tienen un óptimo térmico característico, que disminuye tanto a temperaturas superiores como inferiores. Esto se debe, en primera instancia, a que la actividad enzimática y la integridad de las membranas celulares son afectadas por las temperaturas extremas (Sierra 2006).

Lo anterior puede ser importante desde la perspectiva nutricional, ya que la presencia de taninos es importante en la precipitación de proteínas (Makkar 2003) . En consecuencia, a medida que aumentan las concentraciones de taninos se aumenta la probabilidad de formación de proteína sobrepasante en el rumen, mejorando la respuesta animal al consumo de forrajes, siempre que los contenidos de polifenoles se mantengan entre 2 y $4 \%$ de la materia seca, para que no afecte el funcionamiento ruminal (Makkar 2003).

\section{Literatura citada}

Ashok., K.J. R.M. Vincent \& Nessler. 2000. Molecular Characterization of a hydroxyl Methylglutaryl Coa reductase gene from Mulberry (Morus alba L). Plant. Mol. Biol. 42:559

Barry, T.N. \& D.A. Forss. 1983. The condensed tannin content of vegetative Lotus pedunculatus its regulation by fertilizer application and effect upon protein solubility. Journal of the Science of Food and Agriculture 34: 1047-1056

De Troiani, P.M. 2005. Metabolitos secundarios, Alcaloides, Universidad Nacional de la Pampa.

Georgiev, M., A. Pavlov \& M. Ilieva. 2004. Rosmarinic acid production by Lavandula vera $\mathrm{MM}$ cell suspensions: the effect of temperature. Biotechnology Letters 26: 855-856

Kumar, R. 1992. Antinutritional factors. The potential risks of toxicity and the methods to al- 
leviate them. En: Speedy, A.W. \& P.L. Pugliese. 1992. Legumes tres and other fooder tres as ptrotein source for livestock. FAO animal Production and Health Paper. No. 102.145 pp.

Leinmúller, E., H. Steingass, H \& K.H. Menke. 1991. Tannins in ruminant feedstuffs. Animal and Research and Develovment 33: 9-62

Makkar, H.P.S. 2003 Effects and fate of tannins in ruminant animals, adaptation to tannins, and strategies to overcome detrimental effects of feeding tannin-rich feeds: review. Small Ruminant Research 49:241-256.

Norton, B.W. \& J.H. Ahn. 1997. A comparison of fresh and dried Calliandra calothyrsus supplements for sheep given a basal diet of barley straw. Journal of agriculture Science 129: 485-494
Oncina, R., J.M. Botía, J.A. Del Río \& A. Ortuño. 2000. Bioproduction of diosgenin in callus cultures of Trigonella foenum-graecum L. Food Chemistry 70: 489-492

Posada, S, Montoya, G y otros. 2005. Caracterización de los taninos en la Nutrición de rumiantes 2005.

Sierra, O.J. 2005. Fundamentos para el establecimiento de pasturas y cultivos forrajeros. Editorial Universidad de Antioquia.

Zhang, W., C. Curtin, M. Kikuchi \& C. Franco. 2002. Integration of jasmonic acid and light irradiation for enhancement of anthocyanin biosynthesis in Vitis vinifera suspension cultures. Plant Science 162: 459-468

Recibido: 16 de junio de 2010

Aceptado: 9 de julio de 2010 